\title{
A REMUNERAÇÃO DE PROFESSORES PÚBLICOS MUNICIPAIS NO BRASIL ENTRE 2008 E 2016: UM ESTUDO A PARTIR DA RAIS
}

http://dx.doi.org/10.5902/2318133842084

\author{
Marcus Quintanilha da Silva ${ }^{1}$
}

Resumo

Neste texto apresenta-se a análise da remuneração dos professores públicos municipais brasileiros entre 2008 e 2016. Para tal, adotou-se uma abordagem quantitativa utilizando os dados da Rais em intervalos bienais. A discussão teórica transitou no conceito da remuneração docente como resultado de política pública, em que a alocação de recursos na administração pública é uma decisão política e, na disputa pelo fundo público, o posicionamento do governo federal no período analisado parece ser determinante no aspecto de indução à valorização da remuneração docente. Os resultados indicam uma valorização real da remuneração docente, mas com diferenciação nas formas de contratação e etapas ou modalidades. Além disso, a escolaridade continua a ser diferencial na valorização remuneratória.

Palavras-chave: remuneração docente; financiamento da educação; políticas educacionais; Rais; fundo público.

\section{THE REMUNERATION OF MUNICIPAL PUBLIC TEACHERS IN BRAZIL BETWEEN 2008 AND 2016: A STUDY FROM RAIS}

\begin{abstract}
This article aimed to analyze the remuneration of Brazilian municipal public teachers between 2008 and 2016. To this end, a quantitative approach was adopted using data from Rais at biennial intervals. The theoretical discussion moved on the concept of teaching remuneration as a result of public policy, in which the allocation of resources in public administration is a political decision and, in the dispute for the public fund, the position of the federal government in the analyzed period seems to be decisive in the aspect of inducing the valuation of teaching remuneration. The results pointed out to indicate a real appreciation of the teaching remuneration, but with differentiation in the forms of hiring and stages / modalities. In addition, schooling continues to be a differential in terms of remuneration.
\end{abstract}

Key-words: teaching remuneration; education financing; educational policies; Rais; public fund.

${ }^{1}$ Faculdade São Braz, Brasil. E-mail: marcusquintanlha@gmail.com.

\begin{tabular}{|l|l|l|l|l|r|}
\hline Regae: Rev. Gest. Aval. Educ. & Santa Maria & v. 9 & n. 18 & Pub. contínua 2020 & p. 1-18
\end{tabular} 


\section{Introdução}

organização política e administrativa do Brasil é caracterizada por um sistema
complexo denominado federalismo. Araújo (2005) auxilia na compreensão
inicial deste modelo ao definir como uma espécie de pacto de um número de territórios relativamente autônomos com finalidades comuns num movimento de dupla soberania dos governos subnacionais e a União. Ou seja, a característica inicial de um modelo federalista é a distribuição do poder de decisão a instâncias locais e relativa autonomia de implantação de políticas, em que "vigoram os princípios de autonomia dos governos subnacionais e de compartilhamento da legitimidade e do processo decisório entre os entes federativos" (Abrucio, 2010, p. 41), em que vários locus de poder legítimos atuam simultaneamente. No caso brasileiro o federalismo tem como especificidade o papel do município, inserido em um modelo tridimensional em um federalismo de cooperação, em que se busca equilibrar conflitos federativos e o caráter assimétrico dos entes federados (Cury; Ferreira, 2006).

A partir desse contexto se estabelece um cenário complexo de leitura da efetividade de políticas públicas que envolvem a alocação de recursos, como é o caso da remuneração docente municipal, haja vista que o potencial financeiro e a decisão política de alocação de recursos podem tomar diversas formas no plano local, mesmo com a ação de indução centralizadora do governo federal (Silva, 2019; Araújo, 2013).

Neste trabalho tem-se como objetivo compreender o panorama remuneratório dos professores públicos municipais no Brasil, com base nos anos de 2008, 2010, 2012, 2014 e 2016. A partir de uma abordagem quantitativa, trabalhando com mais de um milhão de vínculos de trabalho em cada ano analisado, compreende-se que uma abordagem deste perfil necessita de um arcabouço teórico e legal para auxiliar na explicação do fenômeno. Nesse sentido, a remuneração de professores como política pública educacional, a necessidade de alocação do fundo público para que a referida política possa ser efetivada, compreendendo essa ação como iminentemente política, e o contexto de disputa pelo referido fundo a partir do governo federal e as ações do mesmo que possam induzir os municípios a valorizarem seus profissionais do magistério no período analisado foram elementos considerados nessa discussão.

\section{Política pública de remuneração docente: o posicionamento do governo federal na valorização dos professores públicos}

A valorização dos professores no Brasil "tem sido um tema recorrente nos debates sindicais, acadêmicos, governamentais e naqueles promovidos pelos meios de comunicação" (Masson, 2017, p. 850), tensão que ocorre em um federalismo em que as principais políticas educacionais são planejadas pela União, mas executadas e financiadas em grande medida pelos Estados e municípios, aonde apenas alguns pactos de indução/adesão são complementados financeiramente pelo governo federal (Fernandes, 2015). Como remuneração compreende-se que se trata da

soma dos benefícios financeiros, dentre eles o salário, acordada por um contrato assinado entre empregado e empregador. O salário é, assim, uma parte da remuneração. No caso do magistério público, a remuneração é composta pelos vencimentos do cargo, acrescida de vantagens 
pecuniárias permanentes estabelecidas em lei, em outras palavras, o salário [...] mais as vantagens temporais, as gratificações, o auxílio transporte etc. (Camargo et al., 2009, p. 342)

Ela faz parte da condição docente, que "refere-se tanto à posição social (competências e condições de trabalho) conferida segundo o grau de importância da função, quanto à remuneração e demais benefícios em comparação com outras profissões" (Camargo; Jacomini, 2011, p. 134), bem como ao estabelecimento de um patamar importante para a melhoria da qualidade da educação (França, 2015). Nesse viés a remuneração é tratada como um ponto importante na valorização do professor, princípio constitucional efetivado a partir da carreira (Grochoska, 2015).

Uma concepção política de valorização do professor pode ser traduzida por lutas, enfrentamentos e disputas históricas, em que o desdobramento da política educacional simboliza o estado atual desse embate (Grochoska, 2015). Nessa perspectiva, compreender a política pública educacional de remuneração docente implica na importância dos marcos legais e a necessidade de alocação do fundo público para sua efetividade.

Camargo e Jacomini (2011) discorrem sobre demarcações legais a respeito da valorização do magistério. Para os autores, a lei n. 5.692/1.971 é um marco histórico, por induzir os sistemas de ensino a construírem seus estatutos próprios do magistério. Todavia, foi a partir de 1988, com a Promulgação da Constituição Federal, que uma série de normativas em âmbito nacional reforçaram e ampliaram a necessidade de se estabelecer uma carreira docente e condições remuneratórias mínimas aos profissionais do magistério (Brasil, 1988, 1996, 2006, 2007, 2008, 2009, 2014).

Diante desse conjunto de normativas, Camargo e Jacomini (2011) entendem que "há garantias jurídicas suficientes para que o professor tenha condições de trabalho, possibilidade de formação e remuneração mínima" (p. 159). A lei e a política pública não resolvem os problemas, mas possibilitam "construir uma nova representação dos problemas que implementam as condições sociopolíticas de seu tratamento pela sociedade e estrutura, dessa mesma forma, a ação do Estado" (Muller; Surel, 2002, p. 29). Nesse sentido, é pressuposto que, no caso da lei, "se faz necessária também para que a sociedade se coloque frente a seus direitos, ou seja, as leis criam uma condição humana de disposição às lutas e enfrentamentos, necessários para conquistas e avanços históricos" (Grochoska, 2015, p. 51).

A ideia de política educacional, portanto, é materializada por meio de ações políticas do ente federado, "em que a valorização do professor se caracteriza como um desdobramento da política educacional” (Grochoska, 2015, p. 47), que, no caso da remuneração docente, implica na necessidade de disputar o fundo público e, consequentemente, sua alocação. Havendo disputa, há política.

Para o atendimento de uma demanda como esta a alocação de recursos é fundamental. No debate com David Easton, cientista político da década de 1950, Poggi (1981) discorre que, na tarefa de governar, a alocação de recursos é um processo a ser institucionalizado em alguns modos de estruturação. Um deles, importante à esta 
pesquisa, é a ordem de valores, em que os objetos são alocados por indicação ou ordenação de alguém ou um grupo. A valorização da remuneração docente necessita estar privilegiada nessa ordem do poder público, num processo que acontece a partir de uma série de fatores políticos e sociais de um determinado contexto.

Apesar da tomada de decisão ser no âmbito municipal, no caso da educação, ela não é isolada de uma política nacional, particularmente por esta competência ser concorrente, mas, com primazia da legislação nacional sobre a local. Dentro de um cenário de influência política onde "não se toma decisão sozinho" (Muller; Surel, 2002, p. 110), a priorização do Poder Público por melhores remunerações dos profissionais do magistério municipal é um processo decisório de natureza política. A forma como um problema se apresenta na agenda política e a ordenação de prioridades do ente, aliadas às alianças políticas com vistas à manutenção do poder, correlacionado às tensões de segmentos sociais, influenciam a execução orçamentária da política pública.

Essa ordenação de prioridades se encaixa num contexto que se denomina disputa política pelo fundo público. Alguns trabalhos são importantes na compreensão do papel do fundo público na modernidade (Oliveira, 1998; Salvador, 2010, 2012). O foco de tais pesquisas situa a discussão na política nacional e internacional, compondo premissas fundamentais para a compreensão deste no plano municipal.

A definição do fundo público consiste na soma de recursos arrecadados pelo Estado em que os tributos, pagos de forma direta ou indireta, envolvem taxações. Caracterizando o termo Salvador (2012, p. 7) elenca que uma das principais formas de constituição do fundo público "é por meio da extração de recursos da sociedade na forma de impostos, contribuições e taxas, da mais-valia socialmente produzida". Para Salvador (2010), o fundo público em seu momento atual "envolve toda a capacidade de mobilização de recursos que o Estado tem para intervir na economia, além do próprio orçamento, as empresas estatais, a política monetária comandada pelo Banco Central para socorrer as instituições financeiras etc." (p. 607). Ou seja, por meio das suas políticas fiscais abre-se um leque de possibilidades de intervenção governamental na economia.

Oliveira (1998) caracteriza o fundo público como um elemento estrutural ao capitalismo contemporâneo, em que a tensão em torno da disputa pela sua alocação é preponderante à acumulação de capital ou na busca de melhores condições de vida à população. O lucro capitalista somente pelo processo de produção de mercadorias se tornou insuficiente nas novas possibilidades de acumulação de capital. Desse processo resulta que o fundo público, conforme o ponto de partida delimitado por Francisco de Oliveira (1998), passou a se vincular a finalidades determinadas anteriormente à sua alocação, em que o detentor do grande capital passa a reconhecer no fundo público uma possibilidade de ampliação de sua taxa de lucro.

A partir de 2006 houve algumas ações, por parte da União, que movimentaram normas de alocação do fundo público na expectativa de promover um cenário de valorização da remuneração docente, destacando o Fundo de Manutenção e Desenvolvimento da Educação Básica e Valorização dos Profissionais da Educação Fundeb e a lei n. 11.738/2008, que instituiu o piso salarial profissional nacional. 
O Fundeb, regulado pela emenda constitucional n. 53/2006 e pela lei $n$. 11.494/2007, é sucessor de política análoga em termos de dinâmica de movimentação do fundo público, o Fundo de Manutenção e Desenvolvimento do Ensino Fundamental e Valorização do Magistério - Fundef -, mas com diferenças significativas em termos de arrecadação, complementação da União e quantidade de matrículas contempladas.

O Fundeb opera por meio de 27 fundos em nome dos Estados e Distrito Federal, em que a redistribuição dos recursos tem por critério o número de matrículas da educação básica, de acordo com os dados do último Censo Escolar, e a modalidade a qual a mesma está vinculada, sendo que, para essa redistribuição, são computados os estudantes matriculados no âmbito da atuação prioritária do ente federado. Em consequência, a aplicação dos recursos do fundo deve ser direcionada à responsabilidade educacional da educação básica prevista na Constituição Federal de 1988. Além disso, anualmente é calculado um valor anual mínimo por aluno - VAA definido nacionalmente, em que as matrículas são ponderadas por dezenove. Aos fundos estaduais que não conseguem arrecadar esse valor a União atua em caráter complementar num piso de $10 \%$ da arrecadação nacional do fundo.

A composição é de $20 \%$ de oito impostos estaduais e repasses constitucionais aos Estados e municípios, em que a subvinculação dos recursos do Fundeb obriga o gestor público a investir não menos de $60 \%$ desses recursos com remuneração docente, sendo que os demais recursos precisam ser destinados obrigatoriamente à manutenção e desenvolvimento do ensino.

Mesmo que os impostos estritamente municipais não entrem no sistema de arrecadação, algumas pesquisas em âmbito nacional e regional apontam para o papel de diminuição da desigualdade e aumento de potencial de investimento para a valorização da remuneração docente (Araújo, 2013; Polena, 2016), apesar do reconhecimento da insuficiência de promover um cenário igualitário remuneratório.

A lei n. 11.738/2008, que tem como objetivo a regulação do piso salarial profissional nacional - PSPN -, um vencimento inicial para a carreira dos profissionais do magistério no Brasil, para uma jornada máxima de 40 horas semanais e a formação mínima, prevista inicialmente no art. 62 da LDB, de ensino médio na modalidade Normal, também se destaca nesse contexto. Além da definição de quem são os profissionais do magistério público da educação básica, a referida lei também regula que, para a jornada de trabalho do profissional, a carga de trabalho em docência com os estudantes deve ser no máximo $2 / 3$ de seu contrato de trabalho, sendo que o restante seja destinado para atividades de planejamento e estudos, dentre outras.

Segundo Fernandes (2013) numa política como esta, regulada pela União e executada pelos entes federados, toma-se como imperativo a redução das desigualdades sociais provocadas pelas políticas econômicas em um cenário de assimetrias regionais no âmbito do federalismo mas, que precisam garantir interdependência e independência dos entes federados, respeitando a autonomia federativa prevista constitucionalmente. Em outras palavras, a regulação de forma centralizada é operada e custeada em um modelo não centralizado, onde a execução da política tem suas variações.

O índice de atualização anual do PSPN é baseado na variação do VAA do Fundeb para uma matrícula dos anos iniciais do ensino fundamental urbano nos dois últimos exercícios anteriores. Ou seja, o reajuste do piso salarial de 2016, por exemplo, foi 
calculado pela variação percentual do valor anual por aluno entre 2014 e 2015, previsto para janeiro de cada ano subsequente. Nesse sentido, a evolução do PSPN está articulada com o Fundeb e a evolução do valor por aluno. Considerando que o Fundeb vincula $60 \%$ de seus recursos ao pagamento da remuneração dos profissionais do magistério, o aumento do valor mínimo por aluno na redistribuição de recursos do fundo implica em maior potencial para os entes federados em alocarem recursos para a valorização da remuneração docente. Nessa ligação, em que o Fundeb se coloca no centro da operação de possibilitar historicamente o endereço dos recursos em MDE para suas finalidades (Fernandes, 2015), implica em compreender que, apesar da política de fundos vincular um percentual mínimo de $60 \%$ para remuneração de profissionais da educação, ela não pode ser considerada como um teto, assim como o PSPN.

Em pesquisa realizada com os municípios brasileiros, 50,7\% destes tem plano de carreira, $45,5 \%$ de gestões municipais que cumprem a lei do piso e $38,9 \%$ ofertam o mínimo de um terço da jornada de trabalho para atividades de planejamento e estudos fora de sala de aula. Com isso, concorda-se que "o grande desafio para a valorização docente, carreira, remuneração e jornada de trabalho ainda permanece. O PSPN tem provocado, na conjuntura econômica e política nacional, todos os estremecimentos possíveis, alguns já superados, outros ainda em curso" (Fernandes, 2015, p. 31).

Ou seja, no federalismo, com equilíbrio cooperativo para implantação e efetividade do PSPN, particularmente no âmbito do Fundeb, compreendendo como uma das principais políticas de valorização da remuneração docente, há um cenário de tensão nas relações intergovernamentais e na efetividade da política no âmbito local, particularmente na superação de traços de patrimonialismo e clientelismo das gestões municipais, arraigados pela construção histórica do federalismo brasileiro (Fernandes, 2013).

$\mathrm{Na}$ discussão supracitada, o fundo público é compreendido como um objeto de valor com várias possibilidades na sua alocação. Apesar de o período de análise deste trabalho ser marcado por algumas ações de indução no plano nacional à um cenário de valorização da remuneração docente, algumas tensões permeiam a disputa pelo fundo público, com o estabelecimento de limites de alocação do fundo público com a lei federal complementar n. 101/2000, conhecida como Lei de Responsabilidade Fiscal - LRF. Estudos como o da Federação das Indústrias do Estado do Rio de Janeiro - Firjan -, que publicou em 2017 um estudo relacionado ao ano de 2016 com base em 4.688 municípios, mostrou-se que ao menos metade dos municípios analisados operavam próximas ao limite estabelecido de alocação de recursos para pagamento de pessoal, o que complexifica a discussão sobre o ente federado municipal e sua autonomia na decisão política de alocação dos recursos.

Mesmo com esse controle, considera-se que a decisão de alocação do fundo público é essencialmente política em que, no caso brasileiro, o posicionamento do governo federal em torno de políticas públicas como o da remuneração docente é fundamental, como na ampliação de aporte financeiro para o investimento em educação via Fundeb ou na legislação que estabelece um piso mínimo remuneratório para os profissionais do magistério. 


\section{A remuneração de professores públicos municipais no Brasil entre 2008 e 2016}

Compreende-se o caráter de complexidade do Estado na decisão política, no qual há uma série de fatores políticos de influência na ordenação de prioridades de uma política pública. Todavia, considerando o limite de análise do objeto em uma abordagem quantitativa, particularmente pelo perfil de casos e variáveis previamente definidas dos municípios brasileiros, compreende-se como postura metodológica "explorar esta base com o auxílio de um programa de tratamento de estatísticas, para finalmente interpretar os resultados de um ponto de vista sociológico" (Selz, 2015, p. 204). Para a autora, cada etapa de exploração é nutrida pela bagagem teórica e conhecimento qualitativo do pesquisador.

Ou seja, entende-se que a estatística não se explica por si, mas é importante para a elucidação de um fenômeno (Selz, 2015). Nessa lógica, o resultado numérico apresentado necessita de um constructo teórico na compreensão de um objeto limitado à médias em âmbito nacional em um estudo longitudinal. Buscar o sentido da ação da gestão municipal não é somente ver a possível evolução da remuneração docente, mas, possíveis ações do poder público que auxiliem a compreender o resultado.

A fonte de informações utilizada neste trabalho, a Relação Anual de Informações Sociais - Rais -, foi instituída pelo decreto presidencial n. 76.900/1975, se constituindo em uma base de dados sobre atividades trabalhistas disponibilizada pelo Ministério do Trabalho. Seu objetivo é subsidiar o controle, elaborar estatísticas e disponibilizar informações sobre o mercado de trabalho, sendo importante em questões como o abono salarial e benefícios previdenciários. Os trabalhadores precisam ser caracterizados pelo empregador, como tipo de vínculo, escolaridade, horas de contrato, remuneração, entre outros, além de precisarem estar vinculados à uma atividade econômica codificada.

A seleção de casos se baseou na natureza jurídica do vínculo empregatício, selecionando os docentes vinculados ao poder público municipal. Além disso, foram utilizados dois filtros aplicados em estudo sobre remuneração realizado pelo Inep no ano de 2017 e disponibilizados em nota técnica: a Classificação Nacional de Atividades Econômicas - CNAE -, envolvendo as atividades vinculadas à educação básica, e a Classificação Brasileira de Ocupações - CBO -, mais específica no que tange à função exercida.

Foram trabalhadas estratificações de professores a partir do vínculo destes com a etapa/modalidade, resultando em seis categorias e vinculação trabalhista, com cinco categorias distintas. $O$ indicador de base foi a remuneração média por hora. Calculou-se a razão entre a remuneração nominal média mensal, as horas contratadas semanais, quantidade de dias úteis por mês e a conversão destes em semanas. Essas operações são descritas conforme a equação a seguir. 
Rem/hora $=\frac{\text { Rem nominal }}{\text { Horas contratadas * } 4,4}$

Em que:

- Rem_nominal = remuneração média mensal lançada pelo empregador na Rais.

- Horas contratadas $=$ horas de contrato semanais lançadas pelo empregador na Rais.

- 4,4 = considera-se como média de dias de trabalho por

mês 22 dias, ou seja, quatro semanas de cinco dias e mais dois dias de complemento.

Para comparação em valores reais a remuneração média dos professores foi corrigida com base no Índice Nacional de Preços ao Consumidor - INPC -, sendo que, a partir de 2008, foi considerado o acumulado do índice inflacionário até o mês de dezembro de 2016. Para 2008 esse percentual acumulado foi de 60,5\%, $2010 \mathrm{com}$ $47,9 \%, 2012$ em $30,52 \%$ e 2014 a $19,23 \%{ }^{2}$.

Os casos que excediam o teto do funcionalismo público em 2016 e que a remuneração por hora fosse menor que o salário mínimo foram excluídos. Nesse sentido, a opção metodológica foi de excluir os trabalhadores que tivessem uma remuneração por hora menor que $R \$ 4,00$, mínimo previsto pelo decreto presidencial n. 8.618/2015, e, de acordo com a lei $n$. $13.091 / 2015$, e maior que $R \$ 33.763,00$ mensais ou $R \$ 191,84$ por hora, por se tratar do teto remuneratório para a administração pública ${ }^{3}$. Essa exclusão foi executada em todos os anos da série histórica analisada na remuneração atualizada pelo INPC.

A partir dessa seleção foram criados cinco bancos de dados relativos aos anos de 2008, 2010, 2012, 2014 e 2016. Em cada um desses bancos foram compiladas informações de todos os trabalhadores da educação, ativos ou que, naquele corrente ano, entraram na inatividade. Nesses municípios selecionados a quantidade de professores na análise foi significativa em todos os anos: 1.298 .573 vínculos em 2008, 1.420 .045 em 2010, 1.612.526 em 2012, 1.734 .804 em 2014 e 1.707 .845 em 2016, compondo informações de 3.286 municípios.

\section{Análise de dados}

As informações analisadas evidenciam que, no período analisado, os vínculos de professores públicos municipais aumentaram significativamente. A ampliação do direito à educação, particularmente na inclusão de estudantes de 4 e 5 anos na faixa de escolarização obrigatória a partir da emenda constitucional n. 59/2009, implicou na maior

\footnotetext{
2 Fonte: calculadora do cidadão do Banco Central do Brasil.

3 De acordo com a referida lei e baseado no inciso XV do art. 48 da Constituição Federal, este teto está associado ao subsídio mensal dos ministros do Supremo Tribunal Federal.

\begin{tabular}{|l|c|c|c|c|r|}
\hline Regae: Rev. Gest. Aval. Educ. & Santa Maria & v. 9 & n. 18 & Pub. contínua 2020 & p. 1-18
\end{tabular}
} 
contratação de profissionais do magistério. Não necessariamente a ampliação de aporte financeiro implicaria em uma resultante de maior remuneração docente, tendo em vista que o aumento das despesas educacionais também teve como objetivo o atendimento à maior quantidade de matrículas.

Entretanto, é perceptível um aumento real da média de remuneração docente por hora no período analisado. Além de aumento real médio, há uma diminuição no coeficiente de variação, ou seja, as remunerações médias têm resultados menos variados no comparativo entre as duas pontas da série histórica, 2008 e 2016.

Outra questão é que os menores rendimentos aumentam significativamente, particularmente até $50 \%$ dos casos que se encaixam nesse perfil. A média remuneratória dos $25 \%$ dos vínculos com menor remuneração aumentou em $56,77 \%$, enquanto no intervalo dos vínculos de docentes de $25 \%$ e $50 \%$ esse aumento foi de $47,43 \%$ e entre $50 \%$ e $75 \%$ a ampliação real foi de $34,86 \%$.

A evolução desse panorama é, possivelmente, resultado de políticas nacionais de valorização da remuneração docente citadas na seção anterior, particularmente por ocasião da instituição do PSPN e a necessidade de se efetivar planos de carreira, cargos e remuneração, mesmo com um cenário em que pouco mais da metade das redes municipais de ensino cumpriam, ao final de 2016, os parâmetros indicados pela lei $\mathrm{n}$. 11.738/2008 (Brasil, 2016). Na tabela abaixo se resume o panorama analisado.

Tabela 1 -

Remuneração média por hora em valores reais dos professores públicos municipais no Brasil 2008-2016.

\begin{tabular}{lcrrrr}
\hline \multirow{2}{*}{ Estatí́sticas } & Rem/hora & \multicolumn{1}{c}{ Rem/hora } & \multicolumn{1}{c}{ Rem/hora } & \multicolumn{1}{c}{ Rem/hora } & \multicolumn{1}{c}{ Rem/hora } \\
& 2008 & 2010 & \multicolumn{1}{c}{2012} & \multicolumn{1}{c}{2014} & \multicolumn{1}{c}{2016} \\
\hline Casos & 1.298 .573 & 1.420 .045 & 1.612 .526 & 1.734 .804 & 1.707 .845 \\
Média & $\mathrm{R} \$ 17,58$ & $\mathrm{R} \$ 18,68$ & $\mathrm{R} \$ 21,43$ & $\mathrm{R} \$ 23,29$ & $\mathrm{R} \$ 23,63$ \\
Mediana & $\mathrm{R} \$ 13,33$ & $\mathrm{R} \$ 14,55$ & $\mathrm{R} \$ 17,46$ & $\mathrm{R} \$ 19,03$ & $\mathrm{R} \$ 19,65$ \\
Coeficiente de Variação & $86,33 \%$ & $84,16 \%$ & $76,66 \%$ & $75,48 \%$ & $72,85 \%$ \\
Até $25 \%$ & $\mathrm{R} \$ 8,52$ & $\mathrm{R} \$ 9,59$ & $\mathrm{R} \$ 11,61$ & $\mathrm{R} \$ 12,62$ & $\mathrm{R} \$ 13,36$ \\
{$[25 \% ; 50 \%]$} & $\mathrm{R} \$ 13,33$ & $\mathrm{R} \$ 14,55$ & $\mathrm{R} \$ 17,46$ & $\mathrm{R} \$ 19,03$ & $\mathrm{R} \$ 19,65$ \\
]50\%;75\%] & $\mathrm{R} \$ 21,11$ & $\mathrm{R} \$ 22,12$ & $\mathrm{R} \$ 25,69$ & $\mathrm{R} \$ 28,15$ & $\mathrm{R} \$ 28,47$ \\
\hline
\end{tabular}

Fonte: Rais (2019).

Na perspectiva de Masson (2017) os planos de carreira no Brasil são efetivados de forma muito variada. As desigualdades remuneratórias no sistema/rede de ensino podem ser mantidas ou ampliadas, algo que, nessa pesquisa de perfil panorâmico, não foi possível investigar.

A política municipal de valorização da remuneração do magistério pode encontrar diferentes nuances na sua implantação, inclusive entre os municípios no interior de um Estado. Esse aspecto da regionalidade ao implantar e executar uma política pública como a remuneração docente pode ser observado na medida em que se agrupam os docentes nos municípios e por Estado, mesmo com o limite da média como medida estatística e as tensões na disputa pelo fundo público no âmbito municipal que carecem de aprofundamento.

Agrupando os municípios por Estado percebe-se que em São Paulo, Acre, Sergipe, Amazonas, Paraná, Mato Grosso do Sul e Rio de Janeiro houve, entre 2014 e 2016, redução do poder de compra de suas remunerações por hora e, no caso do Pará, perdas 
significativas durante a série histórica. Nos demais Estados houve uma evolução de ganhos reais em toda a série histórica, caracterizando, em termos de média, uma perspectiva de valorização da remuneração docente em todo território nacional, com destaques aos municípios da Bahia, Pernambuco, Maranhão, Rio Grande do Norte, Mato Grosso, Ceará e Amapá, com mais de 70\% de ganhos reais entre 2008 e 2016.

Esse panorama aponta para algumas questões contextuais. Mesmo com instrumentos legais em nível nacional como a lei n. 11.738/2008, a vinculação mínima de receitas para 0 investimento em educação definida constitucionalmente e a obrigatoriedade de investir ao menos $60 \%$ dos recursos do Fundeb para remuneração de professores, instituído pela lei n. 11.494/2007 e pela EC n. 53/2006, são pisos mínimos, que, a partir deste patamar, o ente federado pode ampliar o investimento ou manter um cenário de estabilidade. $O$ fundo público em disputa, inclusive no âmbito municipal, em que a educação se apresenta como uma das competências constitucionais do município, demanda recursos financeiros para ser efetivada, assim como outras prioridades que podem, a depender do contexto político e de desenvolvimento econômico local, terem uma ordenação em que a educação e, particularmente, a remuneração docente, não sejam contempladas em ordem prioritária.

Nessa perspectiva, um elemento fundamental na ampliação real da remuneração docente nos municípios é a decisão política de alocação de recursos para tal, aliada ao potencial financeiro do ente federado e as condições do sistema/rede de ensino em termos de atendimento ao direito a educação. A tabela abaixo auxilia nessa compreensão.

Tabela 2 -

Remuneração média por hora em valores reais dos professores públicos municipais agregada por Estado 2008-2016.

\begin{tabular}{|c|c|c|c|c|c|c|}
\hline Estado & 2008 & \multicolumn{2}{|c|}{2010} & 2012 & 2014 & 2016 \\
\hline MA & $\mathrm{R} \$ 8,35$ & \multicolumn{2}{|c|}{$\mathrm{R} \$ 10,27$} & $R \$ 12,72$ & $R \$ 14,58$ & $R \$ 16,93$ \\
\hline $\mathrm{RN}$ & $\mathrm{R} \$ 8,82$ & \multicolumn{2}{|c|}{$\mathrm{R} \$ 11,27$} & $\mathrm{R} \$ 14,62$ & $\mathrm{R} \$ 17,42$ & $\mathrm{R} \$ 20,72$ \\
\hline PE & $\mathrm{R} \$ 9,16$ & \multicolumn{2}{|c|}{$\mathrm{R} \$ 15,25$} & $\mathrm{R} \$ 20,27$ & $\mathrm{R} \$ 16,12$ & $R \$ 16,62$ \\
\hline TO & $\mathrm{R} \$ 9,26$ & \multicolumn{2}{|c|}{$\mathrm{R} \$ 10,51$} & $R \$ 13,39$ & $\mathrm{R} \$ 15,15$ & $R \$ 15,83$ \\
\hline PB & $\mathrm{R} \$ 9,76$ & \multicolumn{2}{|c|}{$\mathrm{R} \$ 10,95$} & $\mathrm{R} \$ 13,44$ & $\mathrm{R} \$ 14,22$ & $\mathrm{R} \$ 14,95$ \\
\hline AP & $\mathrm{R} \$ 9,91$ & \multicolumn{2}{|c|}{$\mathrm{R} \$ 10,32$} & $R \$ 15,98$ & $\mathrm{R} \$ 18,27$ & $\mathrm{R} \$ 19,13$ \\
\hline PI & $\mathrm{R} \$ 11,10$ & \multicolumn{2}{|c|}{$\mathrm{R} \$ 12,03$} & $R \$ 13,24$ & $\mathrm{R} \$ 14,34$ & $\mathrm{R} \$ 14,78$ \\
\hline AM & $\mathrm{R} \$ 11,15$ & \multicolumn{2}{|c|}{$\mathrm{R} \$ 10,28$} & $\mathrm{R} \$ 13,17$ & $\mathrm{R} \$ 18,75$ & $\mathrm{R} \$ 17,10$ \\
\hline CE & $\mathrm{R} \$ 11,38$ & \multicolumn{2}{|c|}{$\mathrm{R} \$ 13,19$} & $R \$ 15,28$ & $\mathrm{R} \$ 19,93$ & $R \$ 23,95$ \\
\hline BA & $\mathrm{R} \$ 11,63$ & \multicolumn{2}{|c|}{$\mathrm{R} \$ 14,60$} & $\mathrm{R} \$ 18,92$ & $\mathrm{R} \$ 21,05$ & $\mathrm{R} \$ 21,00$ \\
\hline SE & $\mathrm{R} \$ 11,90$ & \multicolumn{2}{|c|}{$\mathrm{R} \$ 14,61$} & $\mathrm{R} \$ 19,79$ & $R \$ 20,89$ & $\mathrm{R} \$ 19,78$ \\
\hline $\mathrm{AL}$ & $\mathrm{R} \$ 12,11$ & \multicolumn{2}{|c|}{$\mathrm{R} \$ 16,00$} & $\mathrm{R} \$ 17,01$ & $\mathrm{R} \$ 18,76$ & $\mathrm{R} \$ 18,82$ \\
\hline $\mathrm{RR}$ & $\mathrm{R} \$ 12,17$ & \multicolumn{2}{|c|}{$\mathrm{R} \$ 15,11$} & $R \$ 13,02$ & $\mathrm{R} \$ 15,88$ & $\mathrm{R} \$ 15,79$ \\
\hline MT & $\mathrm{R} \$ 12,40$ & \multicolumn{2}{|c|}{$\mathrm{R} \$ 14,33$} & $\mathrm{R} \$ 17,59$ & $\mathrm{R} \$ 21,19$ & $\mathrm{R} \$ 21,66$ \\
\hline GO & $R \$ 13,02$ & \multicolumn{2}{|c|}{$\mathrm{R} \$ 16,87$} & $R \$ 20,64$ & $\mathrm{R} \$ 22,70$ & $R \$ 23,26$ \\
\hline RO & $\mathrm{R} \$ 13,14$ & \multicolumn{2}{|c|}{$\mathrm{R} \$ 14,14$} & $R \$ 15,92$ & $\mathrm{R} \$ 17,49$ & $\mathrm{R} \$ 17,38$ \\
\hline$M G$ & $\mathrm{R} \$ 13,27$ & \multicolumn{2}{|c|}{$\mathrm{R} \$ 14,18$} & $\mathrm{R} \$ 16,75$ & $\mathrm{R} \$ 18,04$ & $\mathrm{R} \$ 19,60$ \\
\hline SC & $\mathrm{R} \$ 13,68$ & \multicolumn{2}{|c|}{$\mathrm{R} \$ 14,81$} & $\mathrm{R} \$ 16,94$ & $\mathrm{R} \$ 17,92$ & $\mathrm{R} \$ 18,42$ \\
\hline$A C$ & $\mathrm{R} \$ 13,94$ & \multicolumn{2}{|c|}{$\mathrm{R} \$ 15,79$} & $\mathrm{R} \$ 14,88$ & $\mathrm{R} \$ 14,75$ & $R \$ 13,55$ \\
\hline PR & $\mathrm{R} \$ 14,94$ & \multicolumn{2}{|c|}{$R \$ 16,28$} & $R \$ 20,39$ & $\mathrm{R} \$ 22,38$ & $\mathrm{R} \$ 22,81$ \\
\hline ES & $\mathrm{R} \$ 16,30$ & \multicolumn{2}{|c|}{$\mathrm{R} \$ 18,52$} & $\mathrm{R} \$ 20,61$ & $\mathrm{R} \$ 19,96$ & $\mathrm{R} \$ 18,88$ \\
\hline RJ & $\mathrm{R} \$ 16,71$ & \multicolumn{2}{|c|}{$\mathrm{R} \$ 19,08$} & $\mathrm{R} \$ 23,18$ & $\mathrm{R} \$ 25,46$ & $\mathrm{R} \$ 24,53$ \\
\hline Regae: Rev. $G$ & Educ. & aria & v. 9 & n. 18 & Pub. contínua 2020 & p. 1-18 \\
\hline
\end{tabular}




$\begin{array}{llllll}M S & \mathrm{R} \$ 18,25 & \mathrm{R} \$ 18,34 & \mathrm{R} \$ 20,94 & \mathrm{R} \$ 25,72 & \mathrm{R} \$ 22,96 \\ \mathrm{RS} & \mathrm{R} \$ 18,62 & \mathrm{R} \$ 20,03 & \mathrm{R} \$ 22,16 & \mathrm{R} \$ 23,12 & \mathrm{R} \$ 24,35 \\ \mathrm{SP} & \mathrm{R} \$ 19,56 & \mathrm{R} \$ 20,32 & \mathrm{R} \$ 21,02 & \mathrm{R} \$ 21,66 & \mathrm{R} \$ 20,98 \\ \mathrm{PA} & \mathrm{R} \$ 22,52 & \mathrm{R} \$ 31,32 & \mathrm{R} \$ 19,53 & \mathrm{R} \$ 24,40 & \mathrm{R} \$ 23,25\end{array}$

Fonte: Rais $(2008,2010,2012,2014,2016)$. Elaborado pelo autor (2019).

Em decorrência da repartição de responsabilidades educacionais previstas no art. 211 da Constituição Federal de 1988 e no art. 11 da LDB, o maior quantitativo de professores municipais da pesquisa estavam vinculados à educação infantil e ao ensino fundamental, entre $85 \%$ e $88 \%$ das vinculações. Com exceção dos professores das categorias educação especial e outras, é observado um cenário de crescimento contínuo das remunerações. O percentual de professores da educação infantil variou em $14,8 \%$ do total de casos no ano de 2008, 12,6\% em 2010, 17,1\% em 2012, 18,7\% em 2014 e 20,6\% ao final do período analisado. No ensino fundamental, estes percentuais foram de $71,7 \%$, $72,5 \%, 69,2 \%, 67,1 \%$ e $66,2 \%$.

Todavia, a disparidade da educação infantil para as demais etapas/modalidades, debatida em estudos de condições de trabalho e remuneração de professores (Heck, 2014; Alves; Pinto, 2011), foi mantida durante a série histórica. No caso da comparação com o ensino fundamental, por exemplo, maior volume de vínculos trabalhistas nas redes municipais, em 2008 os professores de educação infantil tinham como remuneração média por hora proporcional a $81,24 \%$ dos rendimentos dos professores do ensino fundamental. Em 2016, apesar da ampliação de ambos, essa proporção caiu para $73,09 \%$, indicando que, possivelmente, as políticas locais de ampliação da remuneração docente tenham beneficiado mais os professores do ensino fundamental.

Apesar de a educação infantil ser a etapa com mudança mais significativa no que se refere à ampliação do atendimento a partir de 2009, possivelmente o efeito colateral tenha sido uma política de valorização mais discreta no âmbito municipal, já que estes profissionais não costumam estar vinculados ao mesmo PCCR. Heck (2015) fez uma crítica ao parecer CNE/CEB n. 9/2009, que fundamenta as diretrizes para os novos planos de carreira e de remuneração para o magistério dos Estados, do Distrito Federal e dos Municípios. Segundo a autora, no parecer há uma defesa insuficiente à condição docente destas profissionais.

$\mathrm{Na}$ visão da autora, termos usados confirmam um caráter de resistência em "reconhecer a condição docente das profissionais que atuam com as crianças pequenas em ambiente escolar e também não se propõe a mudar esta condição, uma vez que titubeou em conceber e assumir as educadoras como sendo professoras" (Heck, 2015, p. 39775), posicionamento que, inicialmente, parece ser estendido aos sistemas/redes de ensino municipais na decisão política da alocação do fundo público para a valorização da remuneração docente. Essa tomada de posição pode ser acompanhada pelo tipo de exigência para exercer a função, particularmente no que tange à escolaridade, pois, frequentemente, a formação inicial exigida para atuar na educação infantil é a oferecida em nível médio na modalidade normal, o que poderia possibilitar a ampliação do atendimento com menor impacto financeiro. A tabela abaixo auxilia nesse entendimento. 
Tabela 31 - Remuneração docente por hora em valores reais dos professores públicos municipais agregados por vinculação de etapa/modalidade Brasil 20082016 .

\begin{tabular}{|c|c|c|c|c|c|c|c|c|c|c|}
\hline Etapa/modalidade & \multicolumn{2}{|c|}{2008} & \multicolumn{2}{|c|}{2010} & \multicolumn{2}{|c|}{2012} & \multicolumn{2}{|c|}{2014} & \multicolumn{2}{|c|}{2016} \\
\hline Educação infantil & $\mathrm{R} \$$ & 11,87 & $\mathrm{R} \$$ & 13,24 & $\mathrm{R} \$$ & 14,57 & $\mathrm{R} \$$ & 15,23 & $\mathrm{R} \$$ & 15,70 \\
\hline Ensino fundamental & $\mathrm{R} \$$ & 14,61 & $\mathrm{R} \$$ & 16,20 & $\mathrm{R} \$$ & 18,86 & $\mathrm{R} \$$ & 20,74 & $\mathrm{R} \$$ & 21,48 \\
\hline $\begin{array}{l}\text { Ensino } \\
\text { médio/profissionalizante }\end{array}$ & $\mathrm{R} \$$ & 17,54 & $\mathrm{R} \$$ & 18,85 & $\mathrm{R} \$$ & 20,87 & $\mathrm{R} \$$ & 20,60 & $\mathrm{R} \$$ & 20,94 \\
\hline Educação especial & $\mathrm{R} \$$ & 17,46 & $\mathrm{R} \$$ & 20,05 & $\mathrm{R} \$$ & 19,48 & $\mathrm{R} \$$ & 21,53 & $\mathrm{R} \$$ & 19,84 \\
\hline Equipe pedagógica & $\mathrm{R} \$$ & 15,56 & $\mathrm{R} \$$ & 16,86 & $\mathrm{R} \$$ & 18,38 & $\mathrm{R} \$$ & 19,20 & $\mathrm{R} \$$ & 19,51 \\
\hline Outras & $\mathrm{R} \$$ & 11,50 & $\mathrm{R} \$$ & 12,60 & $\mathrm{R} \$$ & 14,33 & $\mathrm{R} \$$ & 15,25 & $\mathrm{R} \$$ & 15,23 \\
\hline
\end{tabular}

Fonte: Rais $(2008,2010,2012,2014,2016)$. Elaborado pelo autor (2019).

No que tange à vinculação trabalhista a percepção inicial é de que, na comparação entre estatutários, celetistas e contratados, estes últimos têm a menor remuneração. Alguns estudos, como em Ferreira (2013), apresentam análises de contratos terceirizados no serviço público para diminuição de impacto na folha salarial do ente federado.

$\mathrm{Na}$ série histórica, são os estatutários que tem maiores ganhos reais na remuneração por hora dos professores, pois na comparação 2008-2016 houve uma valorização real da média de remuneração docente por hora de $50,17 \%$, enquanto celetistas, contratados e outros tem ampliações percentuais de $30,16 \%, 24,4 \%$ e $5,6 \%$, respectivamente.

Segundo Ferreira (2013) contratos de professores que não seguem a via da efetivação do docente por concurso público como estatutário trazem, entre outras questões, incerteza profissional, redução dos direitos trabalhistas, inacessibilidade aos PCCRs. No caso dos vínculos de trabalho abordados nessa pesquisa, apesar de apresentar uma evolução no número de estatutários, $31,46 \%$, e uma redução no número de celetistas, queda de $8,76 \%$ no comparativo $2008-2016$, as outras formas de contrato aumentaram: contratados e outros ampliaram percentualmente o universo de pesquisados em $95,5 \%$ e $55,7 \%$, respectivamente.

No caso do cenário de ampliação remuneratória dos estatutários, as prováveis explicações podem advir da regulação nacional de planos de carreira, cargos e remunerações, induzidos não só pela lei 11.738/2008, mas pela regulação do Fundeb, seja pela emenda constitucional n. 53/2006 e regulamentados pela resolução n. 2/2009 da Câmara da Educação Básica do Conselho Nacional de Educação, em que a valorização dos profissionais da educação escolar é elencada como um princípio de ensino, bem como pela via da lei n. 11.494/2007, particularmente pelo art. 40, pois indica que os sistemas/redes de ensino deverão implantar seus planos de carreira, visando a remuneração condigna dos profissionais da educação básica da rede pública.

Ou seja, mesmo que os estatutários sejam em maior quantidade em todos os anos da série histórica e tenham ampliado esses vínculos entre 2008 e 2016, houve outras formas de contrato ampliados e sem a mesma valorização da remuneração docente apresentada pelos estatutários. Na tabela seguinte apresenta-se esse panorama. 
Tabela 4 - Remuneração média por hora em valores reais de professores públicos municipais no Brasil agregados por vínculo trabalhista 2008-2016

\begin{tabular}{cclllll}
\hline Vínculo & \multicolumn{2}{c}{2008} & 2010 & 2012 & 2014 & 2016 \\
\hline CLT & $\mathrm{R} \$ 16,31$ & $\mathrm{R} \$ 18,71$ & $\mathrm{R} \$ 19,11$ & $\mathrm{R} \$ 20,87$ & $\mathrm{R} \$ 21,23$ \\
Estatutário & $\mathrm{R} \$ 14,23$ & $\mathrm{R} \$ 16,17$ & $\mathrm{R} \$ 18,78$ & $\mathrm{R} \$ 20,68$ & $\mathrm{R} \$ 21,37$ \\
Outros & $\mathrm{R} \$ 13,92$ & $\mathrm{R} \$ 15,37$ & $\mathrm{R} \$ 15,23$ & $\mathrm{R} \$ 17,42$ & $\mathrm{R} \$ 14,70$ \\
Contratado & $\mathrm{R} \$ 13,44$ & $\mathrm{R} \$ 13,90$ & $\mathrm{R} \$ 15,04$ & $\mathrm{R} \$ 15,31$ & $\mathrm{R} \$ 16,72$ \\
\hline
\end{tabular}

Fonte: Rais $(2008,2010,2012,2014,2016)$. Elaborado pelo autor (2019).

A escolaridade segue como um elemento diferencial na remuneração de professores. Particularmente, na comparação dos professores com ensino médio e ensino superior completos, maior parte dos professores municipais, há uma diferença significativa durante toda a série histórica. Os professores com ensino médio diminuíram a proporção em relação à remuneração média por hora dos professores com ensino superior completo, passando de 81,87\% em 2008 para 78,95\% em 2016. Isso significa que, proporcionalmente, os professores com ensino superior ampliaram sua diferença remuneratória em relação aos profissionais com formação até o ensino médio.

Possivelmente essa relação também é explicada pela política nacional de valorização dos professores, seja no sentido de ampliação da escolarização dos profissionais do magistério, bem como a valorização remuneratória destes pela via dos PCCRs. No caso da primeira questão a LDB orienta, desde sua sanção e as modificações ocorridas pelas leis 12.056/2009 e 12.796/2013, que os entes federados facilitem a capacitação dos profissionais do magistério na formação em ensino superior, seja por mecanismos de acesso e/ou permanência desses profissionais.

Em relação à segunda questão a resolução n. 2/2009 - CNE/CEB orienta para que os PCCRs considerem a formação como um elemento de valorização do profissional do magistério, fomentado pela LDB, lei n. 11.738/2008, emenda constitucional n. 53/2006 e pelo princípio constitucional de valorização do profissional escolar. Nesse sentido, nas redes de ensino em que os planos de carreira estão efetivados, há maior probabilidade de os professores terem ampliação de sua remuneração quando ampliam seu nível de escolaridade. Ressalta-se que a Rais não dispõe de um campo que discrimine os professores com especialização e, por isso, essa informação não aparece nessa descrição inicial e nas análises posteriores.

Tabela 52 - Remuneração média por hora em valores reais dos professores públicos municipais agregados por escolaridade 2008-2016.

\begin{tabular}{llllllll}
\hline \multicolumn{1}{c}{ Escolaridade } & \multicolumn{2}{c}{2008} & 2010 & 2012 & 2014 & 2016 \\
\hline Anos iniciais do EF incompleto & $\mathrm{R} \$$ & 11,34 & $\mathrm{R} \$ 11,62$ & & - & $\mathrm{R} \$ 14,27$ & \\
Anos iniciais do EF completo & $\mathrm{R} \$$ & 11,76 & $\mathrm{R} \$ 12,17$ & $\mathrm{R} \$ 14,84$ & $\mathrm{R} \$ 15,69$ & $\mathrm{R} \$ 16,91$ \\
Ensino fundamental incompleto & $\mathrm{R} \$$ & 10,11 & $\mathrm{R} \$ 11,59$ & $\mathrm{R} \$ 13,96$ & $\mathrm{R} \$ 13,51$ & $\mathrm{R} \$ 14,63$ \\
Ensino fundamental Completo & $\mathrm{R} \$$ & 11,09 & $\mathrm{R} \$ 112,83$ & $\mathrm{R} \$ 14,24$ & $\mathrm{R} \$ 15,10$ & $\mathrm{R} \$ 15,76$ \\
Ensino médio Incompleto & $\mathrm{R} \$$ & 11,13 & $\mathrm{R} \$ 12,51$ & $\mathrm{R} \$ 15,76$ & $\mathrm{R} \$ 15,85$ & $\mathrm{R} \$ 17,44$ \\
Ensino médio completo & $\mathrm{R} \$$ & 12,65 & $\mathrm{R} \$ 14,30$ & $\mathrm{R} \$ 16,29$ & $\mathrm{R} \$ 16,55$ & $\mathrm{R} \$ 16,96$ \\
Ensino superior incompleto & $\mathrm{R} \$$ & 13,47 & $\mathrm{R} \$ 14,53$ & $\mathrm{R} \$ 16,90$ & $\mathrm{R} \$ 17,93$ & $\mathrm{R} \$ 18,68$ \\
Ensino superior completo & $\mathrm{R} \$$ & 15,45 & $\mathrm{R} \$ 17,03$ & $\mathrm{R} \$ 19,36$ & $\mathrm{R} \$ 20,93$ & $\mathrm{R} \$ 21,48$ \\
Mestrado & $\mathrm{R} \$$ & 20,85 & $\mathrm{R} \$ 21,55$ & $\mathrm{R} \$ 24,69$ & $\mathrm{R} \$ 25,34$ & $\mathrm{R} \$ 28,58$ \\
Doutorado & $\mathrm{R} \$$ & 27,99 & $\mathrm{R} \$ 27,25$ & $\mathrm{R} \$ 27,40$ & $\mathrm{R} \$ 30,29$ & $\mathrm{R} \$ 26,23$ \\
\hline
\end{tabular}

Fonte: Rais $(2008,2010,2012,2014,2016)$. Elaborado pelo autor (2019). 
Há uma gama de fatores que são pressupostos norteadores das decisões políticas do poder público que aqui não foram abordadas. Particularmente, no âmbito municipal, as forças políticas locais, aliadas à ordenação de prioridades do grupo político à frente da administração, podem apresentar diferentes nuances de uma política pública como a de remuneração de professores. Nesse sentido, concorda-se com Camargo et al (2009) para quem o tema remuneração docente é determinado por uma série de fatores e agentes com diversos interesses e, deste modo, "expõe sua maior dimensão explicativa, revelando-a como expressão concreta de uma relação de forças em disputa de projetos de sociedade, de escola, de homem, de valorização do ensino: enfim, como luta política" (p. 360).

\section{Conclusões}

Este artigo teve-se como objetivo analisar o panorama da remuneração dos professores públicos municipais no Brasil entre 2008 e 2016. Para tanto, utilizou-se como fonte de informações a Rais para os anos de 2008, 2010, 2012, 2014 e 2016. Como se trata de um mapa nacional, a leitura dos resultados foi realizada a partir da provável efetividade da política pública brasileira de indução à valorização docente no período analisado.

Os resultados indicaram que houve um cenário de valorização real da remuneração de professores públicos municipais. Esse cenário é atribuído, em grande medida, às ações do governo federal a partir de 2006, com a regulação e efetividade do Fundeb, ampliando 0 aporte financeiro para o investimento em educação e vinculação de parte deste recurso para pagamento de profissionais do magistério, o estabelecimento de um piso salarial profissional nacional e as orientações para a construção de planos de carreira, cargos e remuneração.

Todavia, reconhece-se a necessidade de ampliar a investigação numa abordagem qualitativa no âmbito dos municípios, no sentido de analisar aspectos como a implantação de carreiras, a diferenciação remuneratória entre etapas e modalidades, o perfil de crescimento remuneratório e a forma de contratação destes profissionais. Ademais, a partir do reconhecimento da importância da tomada de posição do governo federal para que nos municípios houvesse um movimento nacional de valorização da remuneração docente, o cenário após meados de 2016, em que o funcionalismo público e, particularmente, os professores, passaram a ocupar um espaço secundário na ordenação de prioridades do governo federal, estudos dessa natureza a partir deste ano podem apresentar um cenário de estabilidade ou perda de conquistas históricas da classe docente, como no caso da remuneração.

\section{Referências}

ABRUCIO, Fernando Luiz. A dinâmica federativa da educação brasileira: diagnóstico e propostas de aperfeiçoamento. In: OLIVEIRA, Romualdo Portela; SANTANA, Wagner (orgs.). Educação e federalismo no Brasil: combater as desigualdades, garantir a diversidade. Brasília: Unesco, 2010, p. 39-70.

ARAÚJO, Gilda Cardoso. Município, federação e educação: história das instituições e das idéias políticas no Brasil. São Paulo: USP, 2005. 333f. Tese (Doutorado em Educação) Programa de Pós-Graduação em Educação, Universidade de São Paulo. 
ARAÚJO, Raimundo Luiz Silva. Limites e possibilidades da redução das desigualdades territoriais por meio do financiamento da educação básica. São Paulo: USP, 2013. 401f. Tese (Doutorado em Educação) - Programa de Pós-Graduação em Educação, Faculdade de Educação, Universidade de São Paulo

BRASIL. Constituição da República Federativa do Brasil. Brasília: Senado Federal, 1988.

BRASIL. Lei n. 9.424, de 24 de dezembro de 1996. Dispõe sobre o Fundo de Manutenção e Desenvolvimento do Ensino Fundamental e de Valorização do Magistério, na forma prevista no art. 60, $\S 7^{\circ}$, do Ato das Disposições Constitucionais Transitórias, e dá outras providências. 1996. Brasília: DOU, 26 dez. 1996. Disponível em http://www.planalto.gov.br/ccivil_03/Leis/L9424.htm\#art15\%C2\%A71ii. Acesso em 2 mar. 2018.

BRASIL. Lei n. 11.738, de 16 de julho de 2008. Regulamenta a alínea "e" do inciso III do caput do art. 60 do Ato das Disposições Constitucionais Transitórias, para instituir o piso salarial profissional nacional para os profissionais do magistério público da educação básica. Brasília: DOU, 17 jul. 2008. Disponível em http://www.planalto.gov.br/ccivil_03/_ato2007-2010/2008/lei/l11738.htm. Acesso em 5 jul. 2017.

BRASIL. Lei Complementar n. 101, de 04 de maio de 2000. Estabelece normas de finanças públicas voltadas para a responsabilidade na gestão fiscal e dá outras providências. Brasília: DOU, 2000. Disponível em http://www.planalto.gov.br/ccivil_03/leis/LCP/Lcp101.htm. Acesso em 28 nov. 2017.

BRASIL. Lei n. 11.494 de 20 de junho de 2007. Regulamenta o Fundo de Manutenção e Desenvolvimento da Educação Básica e de Valorização dos Profissionais da Educação FUNDEB, de que trata 0 art. 60 do Ato das Disposições Constitucionais Transitórias; altera a Lei n. 10.195, de 14 de fevereiro de 2001; revoga dispositivos das Leis n. 9.424, de 24 de dezembro de 1996, 10.880, de 9 de junho de 2004, e 10.845, de 5 de março de 2004; e dá outras providências. Brasília: DOU, 2007. Disponível em http://www.planalto.gov.br/ccivil_03/_ato2007-2010/2007/lei/l11494.htm. Acesso em 23 fev. 2018.

BRASIL. Lei n. 13.005 de 25 de junho de 2014. Aprova o Plano Nacional de Educaçao PNE e dá outras providencias. Brasília: DOU, 11 mar. 2008. Disponível em www.planalto.gov.br/ccivil_03/_ato2011-2014/2014/lei//13005.htm. Acesso em 20 jul. 2018.

BRASIL. Emenda constitucional n. 53, de 19 de dezembro de 2006. Dá nova redação aos arts. $7^{\circ}, 23,30,206,208,211$ e 212 da Constituição Federal e ao art. 60 do Ato das Disposições Constitucionais Transitórias. Brasília: DOU, 19 dez. 2006. Disponível em http://www.planalto.gov.br/ccivil_03/constituicao/emendas/emc/emc53.htm. Acesso em 15 fev. 2018.

BRASIL. Relatório de cumprimento do piso salarial profissional nacional pelos entes federativos. Brasília: $\quad 2016 . \quad$ Disponível em http://planodecarreira.mec.gov.br/images/pdf/relatorio_pspn.pdf. Acesso em 20 maio 2018.

BRASIL. Lei n. 9.394 de 20 de dezembro de 1996. Estabelece a Lei de Diretrizes e bases da Educação Nacional. Brasília: DOU, 23 dez. 1996. Disponível em: http://www.planalto.gov.br/ccivil_03/leis/19394.htm. Acesso em 11 mar. 2018.

BRASIL. Manual de orientação da relação anual de informações sociais (Rais): ano-base 2016. Brasília: Ministério do Trabalho, 2016. 
BRASIL. Decreto n. 8.618 de 29 de dezembro de 2015. Regulamenta a lei n. 13.152, de 29 de julho de 2015, que dispõe sobre o valor do salário mínimo e a sua política de valorização de longo prazo. 2015. Brasília: DOU, 30 dez. 2015. Disponível em http://www.planalto.gov.br/ccivil_03/_ato2015-2018/2015/Decreto/D8618.htm. Acesso em 05 abr. 2019.

BRASIL. Resolução n. 2 de 28 de maio de 2009. Fixa as Diretrizes Nacionais para os Planos de Carreira e Remuneração dos Profissionais do Magistério da Educação Básica Pública, em conformidade com o artigo $6^{\circ}$ da Lei n. 11.738, de 16 de julho de 2008, e com base nos artigos 206 e 211 da Constituição Federal, nos artigos 8oㅗ $\S 1^{\circ}$, e 67 da lei n. 9.394, de 20 de dezembro de 1996, e no artigo 40 da Lei n. 11.494, de 20 de junho de 2007. 2009a. Brasília: DOU, 29 mai. 2009. Disponível em http://portal.mec.gov.br/dmdocuments/resolucao_cne_ceb002_2009.pdf. Acesso em 5 jul. 2019.

BRASIL. Parecer n. 9 de 02 de abril de 2009. Revisão da Resolução CNE/CEB n. 3/97, que fixa Diretrizes para os Novos Planos de Carreira e de Remuneração para o Magistério dos Estados, do Distrito Federal e dos Municípios. 2009b. Brasília: DOU, 29 mai. 2009 Disponível em http://portal.mec.gov.br/dmdocuments/pceb009_09.pdf. Acesso em 09 jul. 2019.

BRASIL. Calculadora do cidadão. Disponível em https://www3.bcb.gov.br/CALCIDADAO/publico/exibirFormCorrecaoValores.do?method=e xibirFormCorrecaoValores\&aba=1. Acesso em 10 maio 2019.

BRASIL. Decreto n. 76.900 de 23 de dezembro de 1975. Institui a relação anual de informações sociais - RAIS e dá outras providências. 1975. Brasília: DOU, 24 dez. 1975. Disponível em http://www.planalto.gov.br/ccivil_03/decreto/antigos/d76900.htm. Acesso em 5 fev. 2019.

BRASIL. Lei n. 13.091 de 12 de janeiro de 2015. Dispõe sobre o subsídio de Ministro do Supremo Tribunal Federal, referido no inciso XV do art. 48 da Constituição Federal; revoga dispositivo da Lei $\mathrm{n}$ o 12.771, de 28 de dezembro de 2012; e dá outras providências. 2015. Brasília: DOU, 13 jan. 2015. Disponível em http://www.planalto.gov.br/ccivil_03/_Ato2015-2018/2015/Lei/L13091.htm. Acesso em 21 abr. 2019.

CAMARGO, Rubens Barbosa; GOUVEIA, Andrea Barbosa; GIL, Juca Pirama; MINHOTO, Maria Angélica Pedra. Financiamento da educação e remuneração docente: um começo de conversa em tempos de piso salarial. Revista Brasileira de Política e Administração da Educação, Goiânia, v. 25, n. 2, 2009, p. 341-363.

CAMARGO, Rubens Barbosa; JACOMINI, Márcia Aparecida. Carreira e salário do pessoal docente da educação básica: algumas demarcações legais. Educação em foco, Belo Horizonte, v. 14, n. 17, 2011, p. 129-167.

CURY, Carlos Roberto Jamil; FERREIRA, Naura Syria Carapeto. Federalismo político e educacional. In: FERREIRA, Naura Syria Carapeto (org.). Políticas públicas e gestão da educação: polêmicas, fundamentos e análises. Brasília: Liber Livro, 2006, p. 113-130.

FERNANDES, Maria Dilneia Espíndola. A valorização dos profissionais da educação básica no contexto das relações federativas brasileiras. Educação \& Sociedade, São Paulo, v. 34, 2013, p. 1095-1111.

FERNANDES, Maria Dilneia Espíndola. Em tempo de valorização dos profissionais da educação. In: GOUVEIA, Andréa Barbosa (org.). Valorização dos profissionais da educação: formação, remuneração: carreira e condições de trabalho. Curitiba: Appris, 2015, p. 13-36. 
FIRJAN. Índice Firjan de gestão fiscal. Rio de Janeiro: Firjan, 2017. Disponível em http://publicacoes.firjan.org.br/ifgf/2017/files/assets/common/downloads/publication.pdf.

Acesso em 20 abr. 2019.

FERREIRA, Denize Cristina Kaminski. Os professores temporários da rede pública estadual do Paraná: a flexibilização das contratações e os impactos sobre as condições de trabalho docente. Curitiba: PUCPR, 2013. 185f. Dissertação (Mestrado em Educação) Programa de Pós-Graduação em Educação, Setor de Educação, Universidade Federal do Paraná.

FRANÇA, Magna. Regime de colaboração e o PNE: a valorização dos professores da educação básica - planos de cargos, carreira e remuneração e o piso salarial profissional nacional. In: GOUVEIA, Andréa Barbosa (org.). Valorização dos profissionais da educação: formação, remuneração. Carreira e condições de trabalho. Curitiba: Appris, 2015, p. 13-36.

GROCHOSKA, Marcia Andreia. Políticas educacionais e a valorização do professor: carreira e qualidade de vida dos professores de educação básica do município de São José dos Pinhais/PR. Curitiba: PUCPR, 2015. 269f. Tese (Doutorado em Educação) Programa de Pós-Graduação em Educação, Setor de Educação, Universidade Federal do Paraná.

HECK, Beatriz Terezinha Muraski. A carreira das educadoras da educação infantil no município de Curitiba: integração com a educação ou consolidação na marginalização? Curitiba: PUCPR, 2014. 221f. Dissertação (Mestrado em Educação) - Programa de PósGraduação em Educação, Setor de Educação, Universidade Federal do Paraná.

HECK, Beatriz Terezinha Muraski. Os dilemas da carreira docente na educação infantil. CONGRESSO BRASILEIRO DE EDUCAÇÃO, 12, 2015. Anais ... Curitiba: PUCPR, 2015, p. 39746-39763.

INEP. Nota técnica n. 10/2017/CGCQTI/DEED. A remuneração média dos docentes em exercício na educação básica: pareamento das bases de dados do Censo da educação básica e da RAIS. Brasília, 2017. Disponível em http://www.publicacoes.inep.gov.br/portal/download/1281. Acesso em 18 jan. 2019.

MASSON, Gisele. Requisitos essenciais para a atratividade e a permanência na carreira docente. Educ. Soc., Campinas, v. 38, n. 140, 2017, p. 849-864.

MEDEIROS, Katia Rejane; ALBUQUERQUE, Paulette Cavalcantti; TAVARES, Ricardo Antonio Wanderley;SOUZA, Wayner Vieira de. Lei de responsabilidade fiscal e as despesas com pessoal da saúde: uma análise da condição dos municípios brasileiros no período de 2004 a 2009. Ciência \& Saúde Coletiva, Rio de Janeiro, v. 22, n. 6, p. 1759 1769, 2016.

MULLER, Pierre; SUREL, Yves. Análise das políticas públicas. Pelotas: Educat, 2002.

OLIVEIRA, Francisco. Surgimento do antivalor. In: OLIVEIRA, Francisco (org.). Os direitos do antivalor: a economia política da hegemonia imperfeita. Petrópolis: Vozes, 1998, p. 19-48.

POLENA, Andrea. Uma avaliação do efeito do fundo de manutenção e desenvolvimento da educação básica e valorização dos profissionais da educação (Fundeb) nos municípios do estado do Paraná entre 2007 e 2014. Curitiba: UFPR, 2016. 111f. Dissertação (Mestrado em Educação) - Programa de Pós-Graduação em Educação, Universidade Federal do Paraná.

POGGI, Gianfranco. A evolução do estado moderno: uma introdução sociológica. Rio de Janeiro: Zahar, 1981. 
SALVADOR, Evilásio. Fundo público e políticas sociais na crise do capitalismo. Serv. Soc. Soc., São Paulo, n. 104, 2010, p. 605-631.

SALVADOR, Evilásio. Fundo público e financiamento das políticas sociais no Brasil. Serv. Soc. Rev., Londrina, v. 14, n. 2, 2012, p. 504-522.

SELZ, Marion. O raciocínio estatístico em sociologia. In: PAUGAM, Serge (coord.). A pesquisa sociológica. Petrópolis: Vozes, 2015, p. 202-217.

SILVA, Marcus Quintanilha da. Condições de qualidade das redes municipais de ensino fundamental no Brasil. Curitiba: UFPR, 2017. 227f. Dissertação (Mestrado em Educação) - Programa de Pós-Graduação em Educação, Universidade Federal do Paraná.

SILVA, Marcus Quintanilha da. Remuneração de professores públicos municipais no Brasil: execução orçamentária, partidos públicos e valorização docente (2008-2016). Curitiba: UFPR, 2019. 247f. Tese (Doutorado em Educação) - Programa de PósGraduação em Educação, Universidade Federal do Paraná.

Marcus Quintanilha da Silva é professor na Faculdade São Braz.

Orcid: https://orcid.org/0000-0002-8305-0024.

Endereço: Rua Peabiru, 347 - 83324-480 - Pinhais - PR - Brasil.

E-mail: marcusquintanlha@gmail.com.

Recebido em 29 de janeiro de 2020.

Aceito em 11 de abril de 2020.

(c) (i) 